\title{
RESTORING A CLASSIC CASTER - MAKING THE CASTER YOU HAVE BETTER ${ }^{\star}$
}

Chad Byron Donovan ${ }^{1}$

\begin{abstract}
There is a strong need in North America and other major steel producing markets where major capital investment in new equipment has been minimal over the past several years to make improvements to existing casting machines. In many cases, very cost effective improvements can be made to existing equipment in order to maximize the efficiency and production of an older designed continuous caster, a classic caster. SMS Group and its predecessor companies have been maintaining continuous casting molds for over forty years. This experience has allowed SMS Group to intimately understand the advantages and disadvantages of each design. The most vital component of the continuous caster is the mold copper design, as it has the most influence over the ability to cast a quality product. Updating to a modern copper design is less complicated than most steel producers think and the benefits are significant. Premium mold coatings such as UniGuard® and NanoGuard® allow casters to guard against exposed copper and wear while producing quality products for record campaign lengths.
\end{abstract}

Keywords: Mold; Mould; Coatings; Continuous casting.

Chemical Engineering graduated at Pennsylvania State University, University Park; Mathematics/Engineering graduated at Saint Vincent College - Latrobe; and General Manager of Sales and Innovation for SMS Technical Services, Oil City, Pennsylvania, USA. 


\section{INTRODUCTION}

In an ever increasingly competitive environment for steel production, many continuous casters are in need of significant upgrades to their equipment in order to remain cost competitive. Such improvements can be strictly related to reducing costs by increasing equipment availability or, in other cases, be more focused on allowing a caster to increase casting speed, improve product quality or even potentially cast value-added product grades not previously attempted. The average age for a continuous slab casting machine in North America is over twenty-five years old, and capital spending on new casting machines has been limited for nearly fifteen years.

What is a facility manager to do when years go by and it seems that capital request after capital request has fallen on deaf ears and the facilities continue to fall farther and farther behind the curve? Instead of throwing up your hands and resigning to the idea that you will have to wait another year and need to just patch things up until "things get better", consider improving what you have. Let SMS Group restore your caster transforming it into something that better allows your facility to compete in this new global marketplace.

SMS Group has been in the continuous casting mold and segment repair business since the inception of continuous casting in North America during the 1960's. The experience in maintaining the casting equipment of all major OEMs by SMS Group over what is fast approaching fifty years has provided us intimate knowledge of many casting equipment designs, and what cost effective solutions can be made to improve the reliability of this equipment. Steel producers are faced with increasing customer quality demands on existing steel grades, plus the demands of casting new, higher alloy grades, which in several cases is stretching the capability limits of the existing casting machines to deliver a slab of suitable quality. While for other casters the desire is to simply increase tonnage and maximize the productivity of their facilities.

The mold is only part of the process and other improvements to the continuous casting machine such as secondary cooling, overall machine taper and use of segment roll overlays are all interesting topics. However, the fact remains that the mold is the point of initial solidification and paramount in producing quality steel, a product defect occurring in the mold cannot be rectified in the remainder of the caster. Therefore, the focus of this paper is to present a summary showing the wide variety of mold improvements available for different types of thick, medium and thin slab continuous casting machines.

\section{IMPROVED COPPER DESIGNS}

One of the most common improvements that can be made for an aging continuous casting machine is to redesign the cooling geometry of the copper mold plates. These mold liners must be replaced when they achieve scrap or minimum thickness regardless of design, and rather than purchasing the same old copper design, it is a wise decision to have the existing coppers modeled. Such modeling can be very detailed with 3-D thermal models created and a variety of boundary conditions evaluated similar to what may be done for a new casting machine. An alternative and often less time consuming and costly approach is to optimize a copper design with boundary conditions that are established for a given casting machine. There is no sense in creating an optimized copper design for a given water flow rate and pressure if capital money is not available to increase or improve mold water pumps 
for example. Typically, copper designs are modeled to achieve the most effective slot root velocity, taking into the account the maximum volume and pressure of mold water that could be supplied to the caster. The most common modeling is 2-D thermal view aimed at achieving the most uniform meniscus hot face temperature possible over the entire range of copper thicknesses from new to minimum thickness. Figure 1 below is a comparison showing two 2-D section views taken at meniscus height one showing the projected temperatures at new or maximum copper thickness while the other is at scrap or minimum copper thickness.

\section{Maximum Copper Thickness}

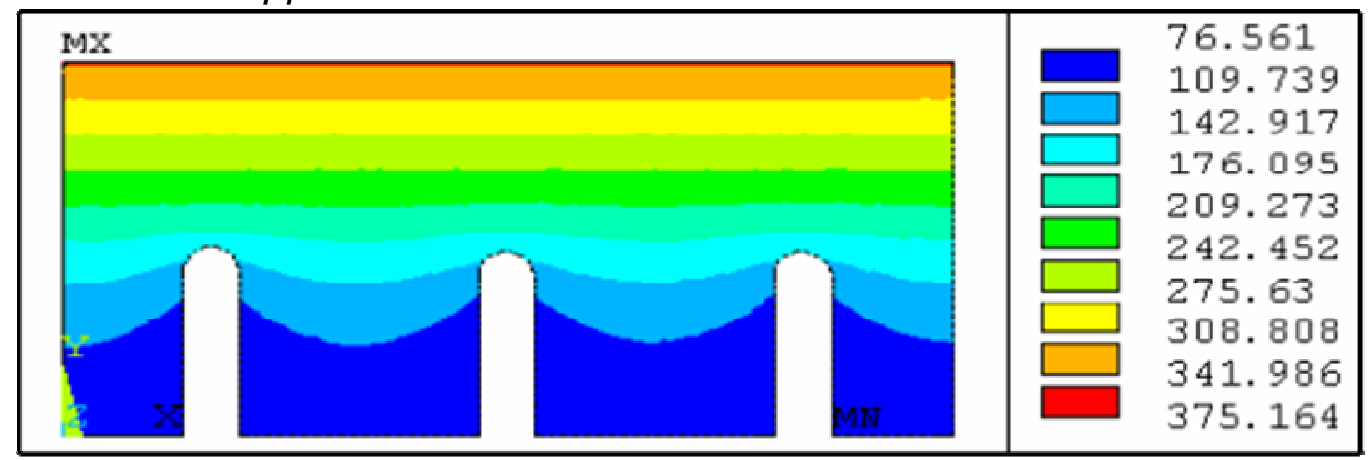

\section{Minimum Copper Thickness}

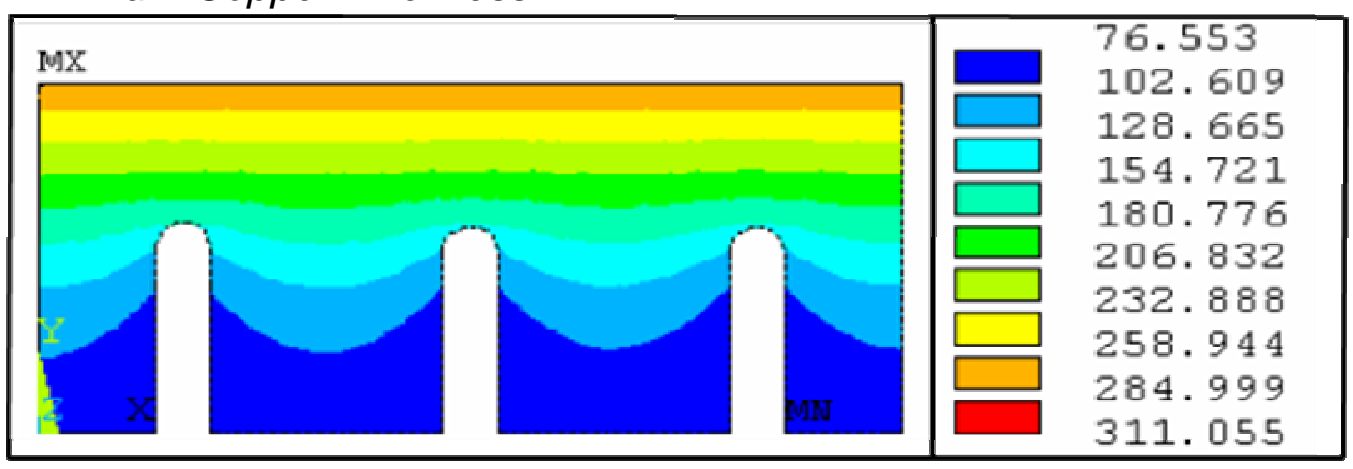

Figura 1: 2-D model showing meniscus at "New" and "Scrap" thickness

Many older copper designs have especially poor heat removal uniformity at or near minimum copper thicknesses. This inconsistency in hot face temperatures results in less than optimum mold powder performance and erratic heat removal which can cause an increase in longitudinal face cracks. Modern copper designs aim at providing uniform meniscus hot face temperatures over the entire range of useable copper thicknesses.

If certain casting conditions are targets such as mold hot face temperatures, the model can be set-up to achieve a desired hot face temperature for a given range of water flow rates and pressures. Most optimized copper designs today will offer some type of slalom slotting to allow for more uniform cooling of the bolting areas on the cold side of the copper. Moreover, the effective cooling length of the mold can be increased without increasing the height of the mold and effects of inadequately cooled areas related to mold level control pockets can be minimized. A very achievable goal after doing proper modeling and redesign of a mold copper liner is a $5^{\circ} \mathrm{C}$ or less variance in meniscus hot face temperature and, in many cases on new coppers, this variance has been documented to be as low as 2 to $3^{\circ} \mathrm{C}$ [1]. Figure 2 below is a basic broadface thermal model comparing older slot design versus a modern slalom slotting design. 

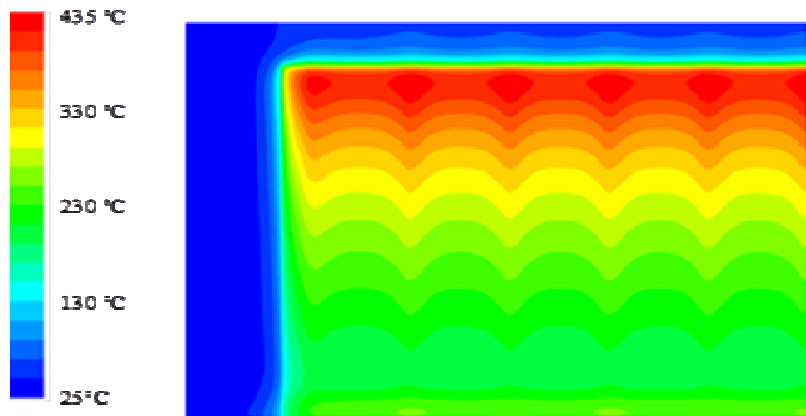

Conventional

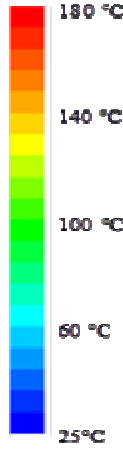

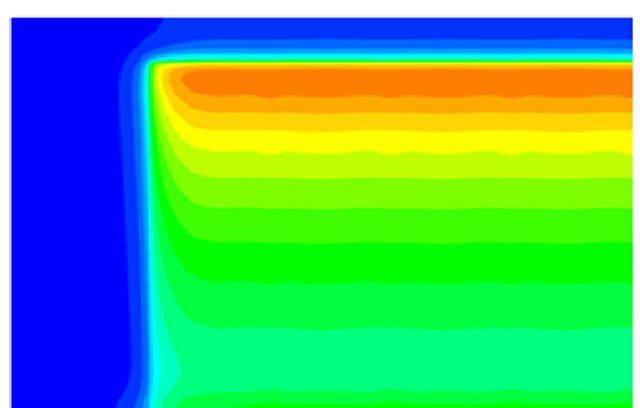

Slalom Slots

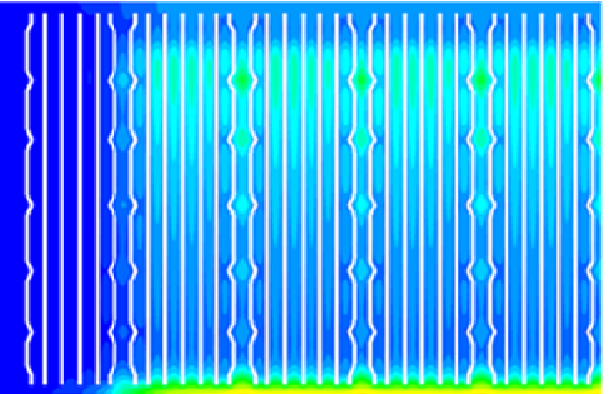

Figure 2: Thermal uniformity comparison between standard and slalom slotting

Copper modeling can be used to create a design that allows for increases in casting speeds to occur without being detrimental to the product quality [1]. Uniform meniscus heat removal resulting from an optimized slotting design allows for reductions in longitudinal face cracks and, in some cases, even transverse corner crack type defects. Moreover, casters that have implemented such improvements in copper design see improved mold life as issues with meniscus cracking of the copper are minimized and mold coatings used to protect the coppers perform better.

\section{MOLD COATING USEAGE}

Nearly every continuous casting machine can benefit from the use of mold coatings. There are a variety of mold coating options available that can be used to improve the performance of the mold. Due to variances in continuous caster design and casting parameters, different molds have different hot face temperatures as well as different mold wear or erosion issues. Coating types and configurations should be matched to an individual casting machine. Such benefits from mold coatings include the following:

- Step and full face mold coatings protect the lower portion of the mold from wearing. This maintains designed taper and dimensions of the mold cavity allowing for molds to remain in service for longer campaigns.

- Step and full face coatings prevent wear at the mold exit, and in return eliminates copper from depositing on the strand which is a primary cause of "star" type or "spider" crack defects [2].

- Full face mold coatings offer the added benefit of thermal insulation in the upper part of the mold that helps promote a more uniform meniscus hot face temperature. 
- In some cases, full face mold coatings can be used to increase hot face temperatures, thereby allowing thinner coppers to perform better or improve the surface finish of the "as-cast" product.

- Full face coatings typically result in less meniscus erosion and cracking versus an unprotected meniscus. Having a mold coating at meniscus height also helps protect the copper from erosion and scratching that occur due to the numerous on-line width changes that many casters are now forced to make.

Over the past decade, the focus and advancements in regards to mold coatings has been such that many casters have transitioned from mold copper wear being a primary reason for mold removal to corner gaps and/or foot roll support being the leading cause of a mold needing to come out of service [3,4]. SMS Group has been a global leader in the development of mold coatings suitable for use on continuous casting molds. In addition to offering traditional caster mold coatings such as chrome, copper, nickel and nickel-cobalt alloys, SMS Group has two mold coating products that have been proven to significantly increase caster mold life. The most commonly used premium mold coating offered by SMS Group is UniGuard®, which is a combination thermal spray and electroplated coating option [3,4]. The first trials using UniGuard® occurred over ten years ago, and, over the past few years, SMS Group has developed another alternate premium coating named NanoGuard®. The NanoGuard® coating has proven to be successful in improving mold life over basic nickel and nickel alloy coatings. Below in Figure 3 is a simple graph showing the wear resistance of different mold coating products offered by SMS Group.

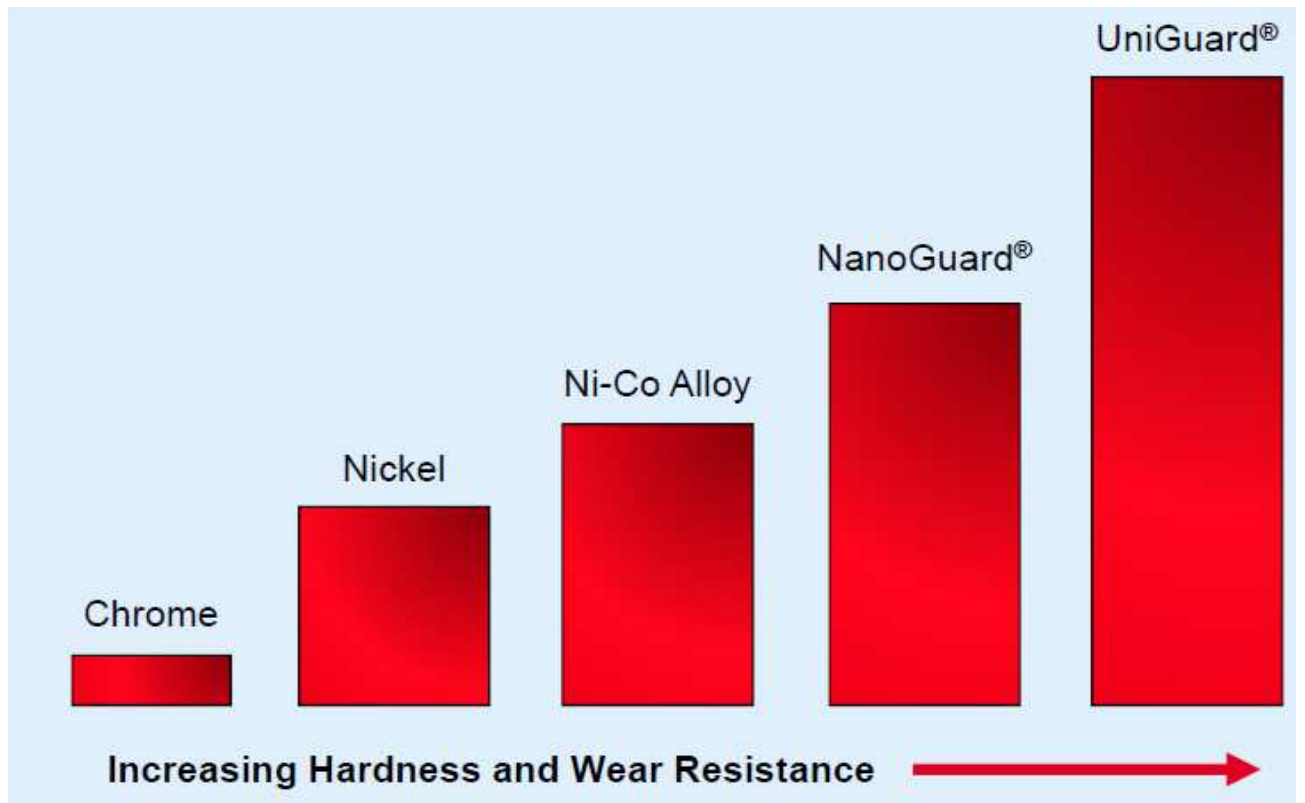

Figure 3: SMS Group mold coating products

UniGuard® coated mold coppers have allowed numerous casting machines to achieve record tonnages on broadface and narrowface copper plates, with several casting machines breaking the 500,000 tons cast plateau. Below in Figure 4 is a photo of an ArcelorMittal Dofasco cassette style copper that had been coated with UniGuard® and reached 500,000 tons of service. Even after achieving this high tonnage, the condition of the hot face was so good that this broadface copper was installed into another mold with a set of newly refurbished narrowfaces to continue its service campaign. It should be noted that this particular copper design was optimized 
for improved cooling by SMS Group in 2009, and this improved cooling geometry has partially contributed to the performance of the mold coatings on these coppers.

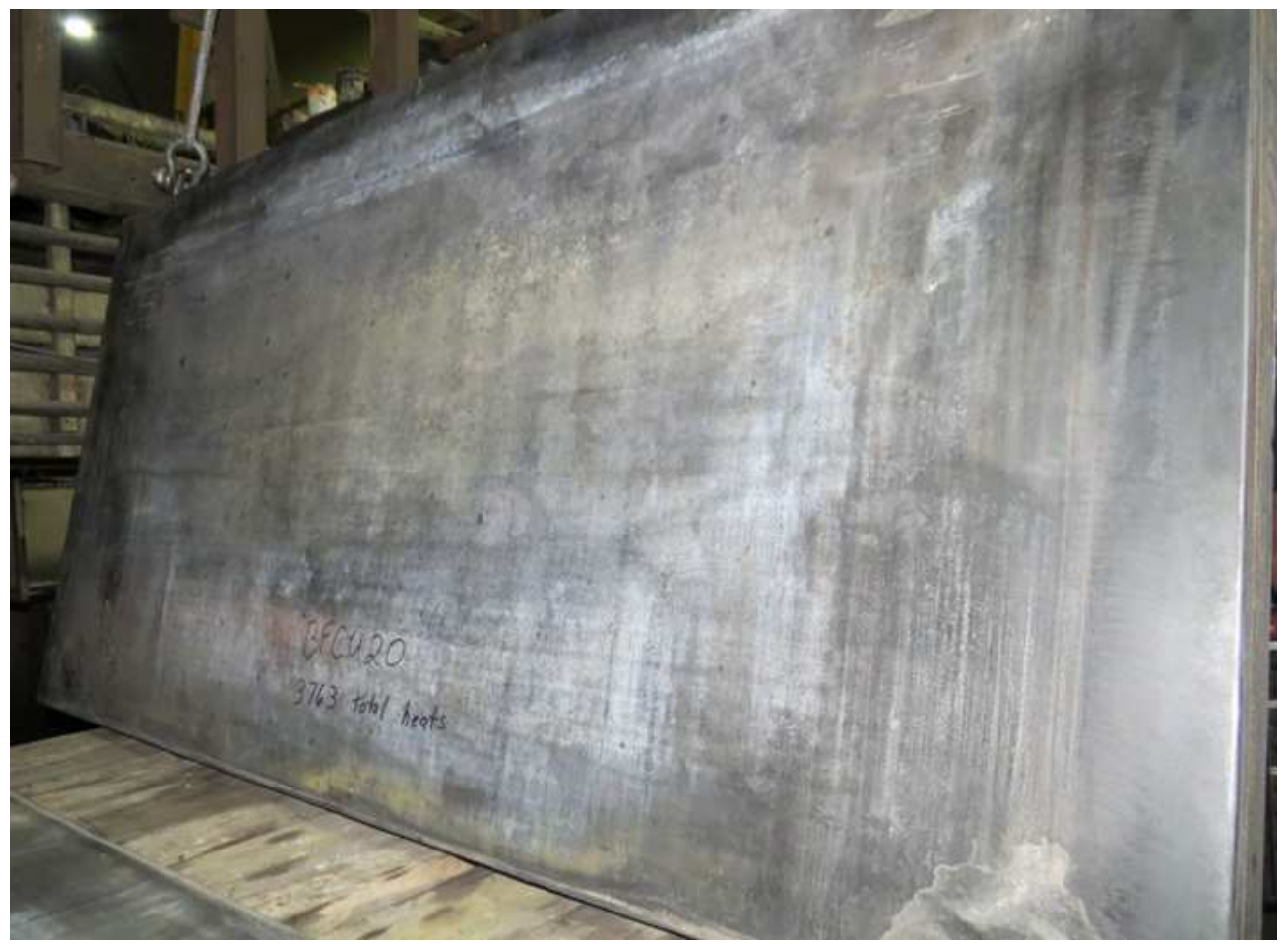

Figure 4: UniGuard $\AA$ coated ArcelorMittal Dofasco \#2 broadface copper assembly after 500,000 tons cast

Although UniGuard® was highly successful for many casting machines a nickel based alloy was still a preferred option for some casters. Several years ago, SMS Group began developing a nickel based super alloy. In 2010 controlled customer trials began at a select few casters. After optimization of the alloy and coating hardness, SMS Group has now begun promoting this new coating option under the trade name NanoGuard®. This nickel based coating is an electroplated tertiary alloy that has a dense nanocrystalline structure, which is stable at high casting temperatures. The typical hardness of NanoGuard® is 500 to $650 \mathrm{HV}$ and can be plated in a full face or step coating configuration. For certain applications the coating hardness can even be pushed higher than $700 \mathrm{HV}$. However, increased hardness typically results in higher internal stress of the deposit and can result in excess cracking of the coating during service. In comparison to Ni-Co mold plating with hardness values in the range of 250 to $400 \mathrm{HV}$, the NanoGuard® mold coating has increased mold life in excess of $50 \%$. Figure 5 , shown on the following page summarizes the successful use of NanoGuard® at Nucor Decatur (an SHI designed high speed casting machine) over the past several years. 


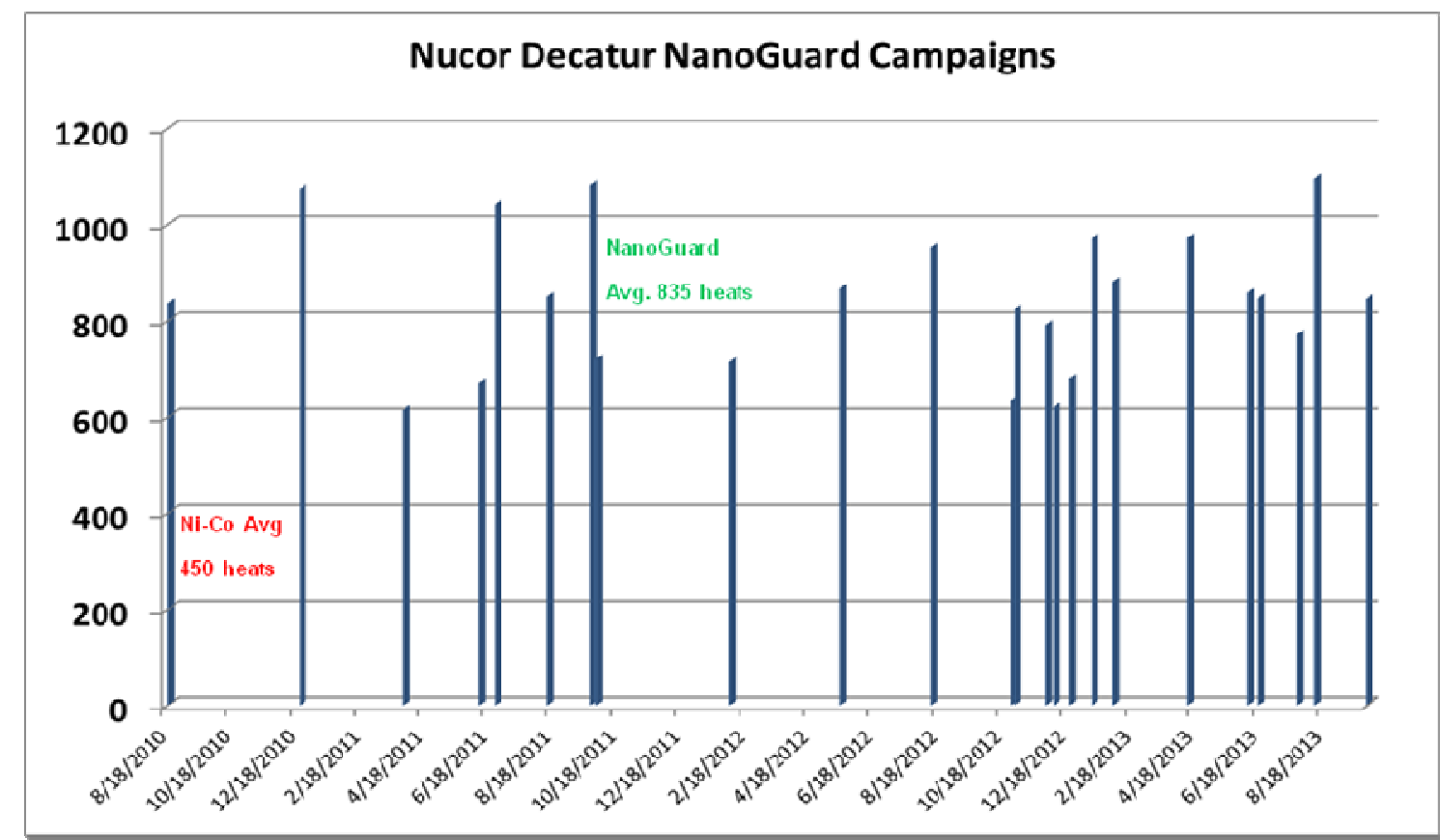

Figure 5: NanoGuard® coated broadface copper campaigns for Nucor Decatur 2010 to 2013

\section{WATER JACKET UPGRADES}

Many North American casting machines have aging carbon steel water jackets and are running significantly longer campaigns between mold repairs. These factors, combined with other issues such as equipment staying out of service longer and, in some cases, casters being dormant for many months, has made scale exfoliation issues a more common reason for molds being removed from service. Moreover, scale causing blockages and biased water flow in the mold copper cooling passages can result in intermittent quality problems such as longitudinal face cracking and in the worst of cases breakouts [5]. In some cases the amount of exfoliated scale collected inside the continuous casting mold can be so intense and water flow so obstructed that the copper and water jacket assembly can be severely overheated. This can result in significant water leaks between the copper and water jacket which can become a serious safety issue if large amounts of water enter the mold cavity and directly contact the liquid steel. Below in Figures 6 and 7 are pictures showing severe scale blockages found in the gun drilled holes of a high speed casting copper and water jacket.

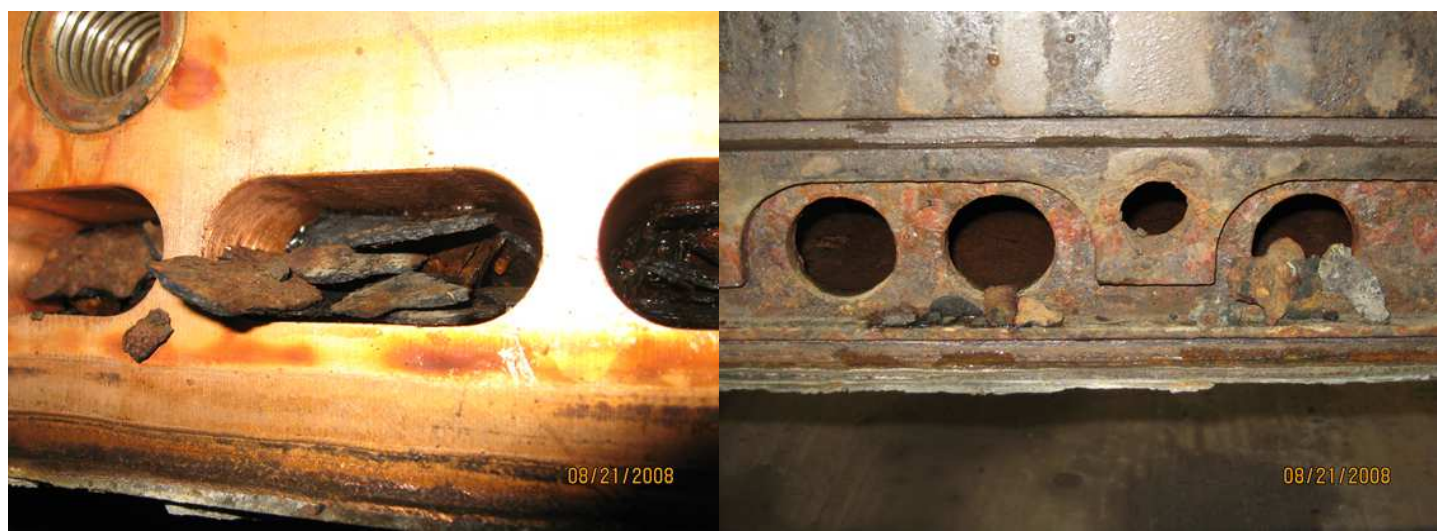

Figures 6 and 7: Scale blockage in connecting holes of a high speed copper and Scale in water jacket water feed ports 
SMS Group has developed multiple options and solutions to address this issue of internal scale forming inside water jackets.

- Addition of access ports to allow for cleaning and removal of scale as well as the ability to examine and inspect all inner surfaces of the water jacket with minimal obstructions

- Internal blasting and subsequent powder coating to remove and prevent internal corrosion

- Use of custom engineered miniature strainers to prevent scale large enough to block the water passages from exiting the water jacket and lodging itself in the copper cooling slots or gun-drilled holes

Improper heat removal caused by these intermittent water blockages in a high speed caster can easily result in "caster folds" or small longitudinal face cracks on the strand. Some casters have implemented all improvements, internal blasting, powder coating and strainer baskets to eliminate the possibilities of scale causing such quality issues. The picture below, Figure 8 , shows the bottom plenum chamber of a $\mathrm{CSP} \AA$ mold water jacket after all operations were performed.

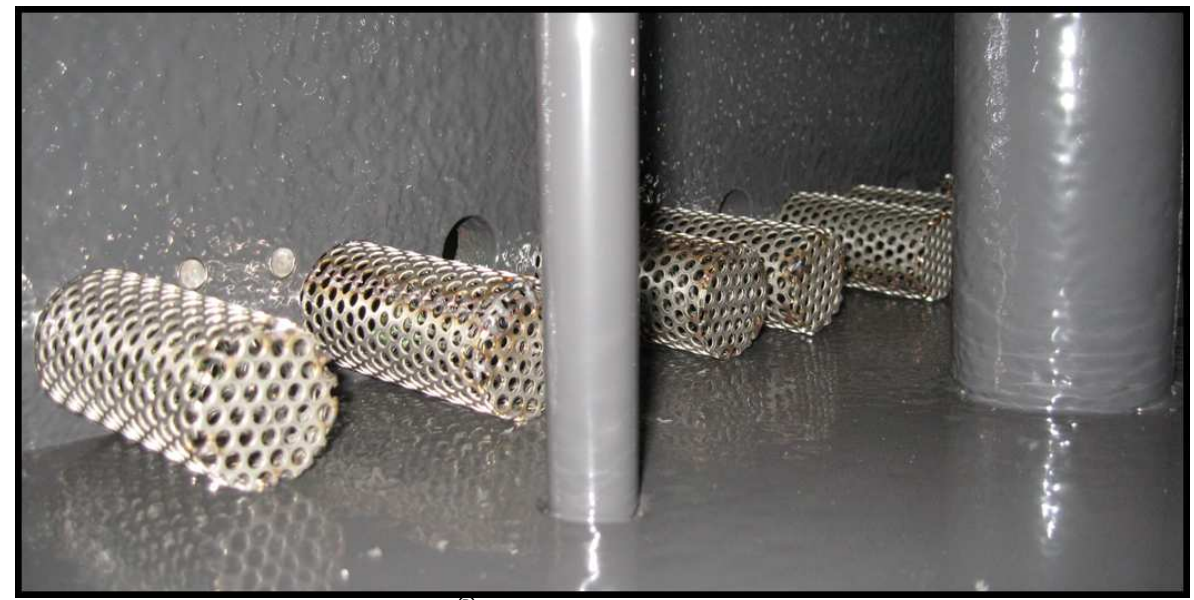

Figure 8: Bottom plenum of $\mathrm{CSP}^{\circledR}$ water jacket showing powder coating and strainers

\section{BREAK OUT DETECTION AND THERMAL MONITORING SYSTEMS}

Breakout avoidance systems and more elaborate thermal map systems used by many continuous casters are important tools for caster operators, and these systems are highly dependent on thermocouple reliability. SMS Group and its predecessor companies have decades of experience in repairing and designing thermocouples utilized on casting molds. Two types of thermocouple designs that are most commonly used today are welded Constantan and spring loaded, two-wire style thermocouples. Of course there are several other thermocouple designs and variations that SMS Group maintains and has made various design improvements to either increase their reliability or decrease the cost in maintaining them. SMS Group has modified coppers and water jackets for dozens of casters in order to originally install BOA/BOD systems or increase the density of the thermocouples by adding locations.

Spring loaded thermocouples are common in the latest caster designs, and although much better than many older two-wire style thermocouples, proper maintenance practices and design are vital to making them as reliable as casters would like them to be. The advantages of the spring loaded thermocouples include: the ability to replace a malfunctioning probe without disassembly of the copper, spring tension on 
the TC junction, two wires per location providing a clean and reliable signal, and reusability. Older two- wire thermocouple systems can be easily replaced by spring loaded designs. Proper maintenance of spring loaded thermocouples as well as the correct design and construction on the thermocouples can result in such systems having high reliability. Figure 9 on the following page is a photo showing some robust spring loaded thermocouples designed by SMS Group with the shorter probe being a narrowface thermocouple and the longer probe being a broadface thermocouple.

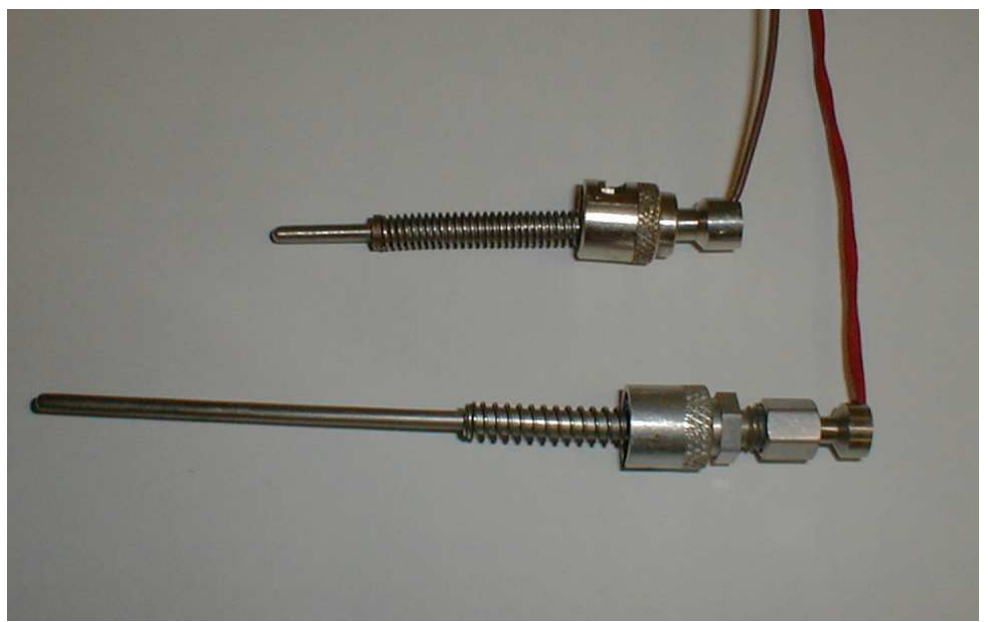

Figure 9: Spring loaded thermocouple examples

One of the original, simple and most reliable types of thermocouples is a Constantan rod that is welded directly to the mold copper plate with a single wire soldered directly to the end of the Constantan rod (shown below in Figure 10). The advantage of this thermocouple type is its simplicity; the disadvantage is that the weld joint could break or that a loss of the common ground would result in loss of all thermocouple signals on a given copper plate. Over the past several years, a new welded Constantan rod design implemented by SMS Group has been effective in eliminating these issues. The new design, shown below in Figure 11, utilizes a large diameter slug of Constantan that is welded to the copper at the thermocouple locations and then a Constantan rod is threaded into this Constantan slug. The larger diameter weld joint and the fact that the thermocouple rod can be removed during refurbishment leaving nothing above the cold face exposed, prevents breakages of the thermocouple. Additionally, the new design includes multiple grounds to decrease the chances of losing the common ground.
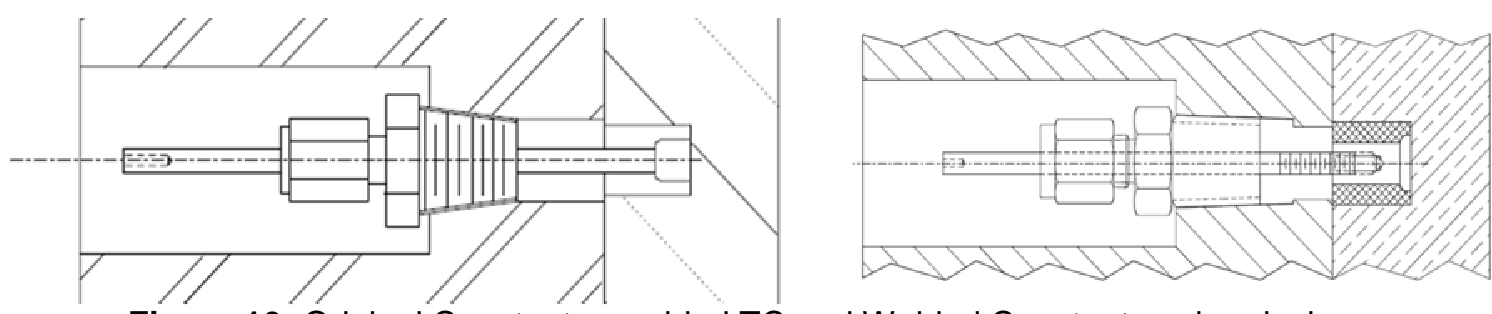

Figure 10: Original Constantan welded TC and Welded Constantan slug design

\section{WIDTH CHANGE UPGRADES}

In addition to adding on-line width change capabilities to older casting machines without such ability, SMS Group has performed a variety of upgrades to the width change, mold clamping and end wall mechanisms for several existing casters. Below 
is a list of the various types of upgrades made to such components of existing casting machines:

- Replacement of Acme type spindle screws with precision ball screws to decrease backlash

- Modification to end frames and spindle design to increase spindle stroke to allow a wider range of casting widths

- Rebuilding or replacement of gear boxes and/or gear reducers to minimize backlash and improve mold life

- Implement limit switches to prevent over travel of the various endwall mechanism screw and nut assemblies

- Electrical upgrades replacing obsolete and/or expensive DC or AC drive motors with current commercially available and inexpensive more common AC drive motors

- Fitting inclinometers to narrowface assemblies to allow for on-line monitoring of narrowface taper

- Dynamic mold clamping utilizing load cells and feedback control to monitor and adjust mold clamping forces

- Design of center-divider or center block to allow for twin casting, increasing caster productivity as two narrow strands can be cast through one casting machine

In some cases, the above upgrades are straight forward and easily implemented; however, there are cases where complete new narrowface assemblies or extensive modifications to the mold frame and mold clamping positions are necessary. In 2009, SMS Group completely re-engineered the VAl designed cassette style mold at ArcelorMittal Dofasco. From start-up in 1996, this casting machine had struggled with corner gap issues. After less than 500 heats, the corner gap per side was often in excess of $1 \mathrm{~mm}$, requiring the mold to be removed from service. Numerous modifications were made to this mold, but the primary issue related to these corner gap issues was poor location of the clamping positions. Shifting the clamping positions closer to the bottom and top of the mold cavity was the key to eliminating this problem. The complexity of the mechanical arrangement was reduced by eliminating the number of components required in the system to maximize the reliability of the width/taper adjustment system. All external drive shafts, universal joints and clutches were eliminated as part of the re-design. 1 Today, this casting machine is able to cast consistently in excess of 3000 heats while maintaining excellent corner gaps, below $0.5 \mathrm{~mm}$ per side. Figure 12 below is a schematic showing the relocation of the clamping positions as well as some of the other upgrades made to this casting machine. 


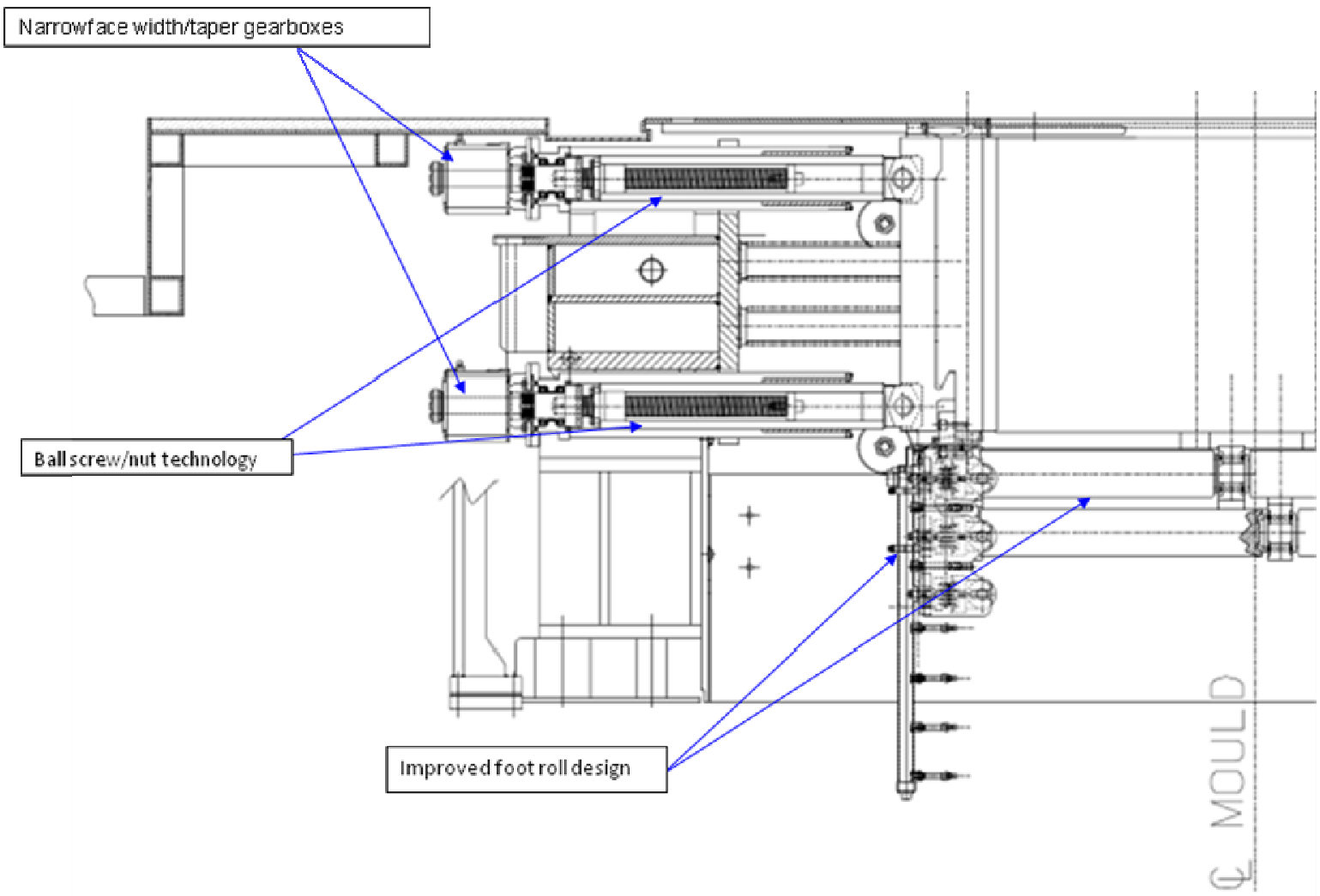

Figure 12: Schematic showing redesigned ArcelorMittal Dofasco \#2 caster mold

\section{FOOT ROLL IMPROVEMENTS}

For many casters, foot roll wear and deflection have become an increasing concern as molds are able to be pushed for hundreds of thousands of tons more than what the original design intended. In the case of broadface foot rolls, the primary issue is deflection of the rolls either due to insufficient roll cooling or weak and/or poorly maintained supporting brackets. Corrosion and roll cracking can also be a problem contributing to poor broadface support. For most casters, the narrowface or lateral strand guides are even more problematic as the supporting frames for the narrowfaces are usually less robust. There can be significant force on the narrowface foot roll assemblies depending on tapers used and the grades being cast. Depending on the original design, these issues may be the result of deflection in the roll bracket, excessive clearance in the roll holder, excessive clearance of the bearing or shaft due to wear during the increased campaign lengths.

In order to decrease roll wear, deflection and corrosion, switching roll materials to 17$4 \mathrm{PH}$ stainless steel is common. In some cases, additional roll cooling and resistance to deflection is available by increasing the roll diameter and/or grooving the rolls. Many redesigns of both broadface and narrowface foot roll frames incorporate break out acknowledgement tubing. This is a simple arrangement where tubing is pressurized, and a leak in this tubing caused by a melt through from liquid steel below the mold results in an alarm confirming that a break out has occurred. This confirming alarm usually results in the caster being immediately ceased to minimize damage from the break out. Below in Figure 13 is a photo showing the copper break out confirmation tubing. 


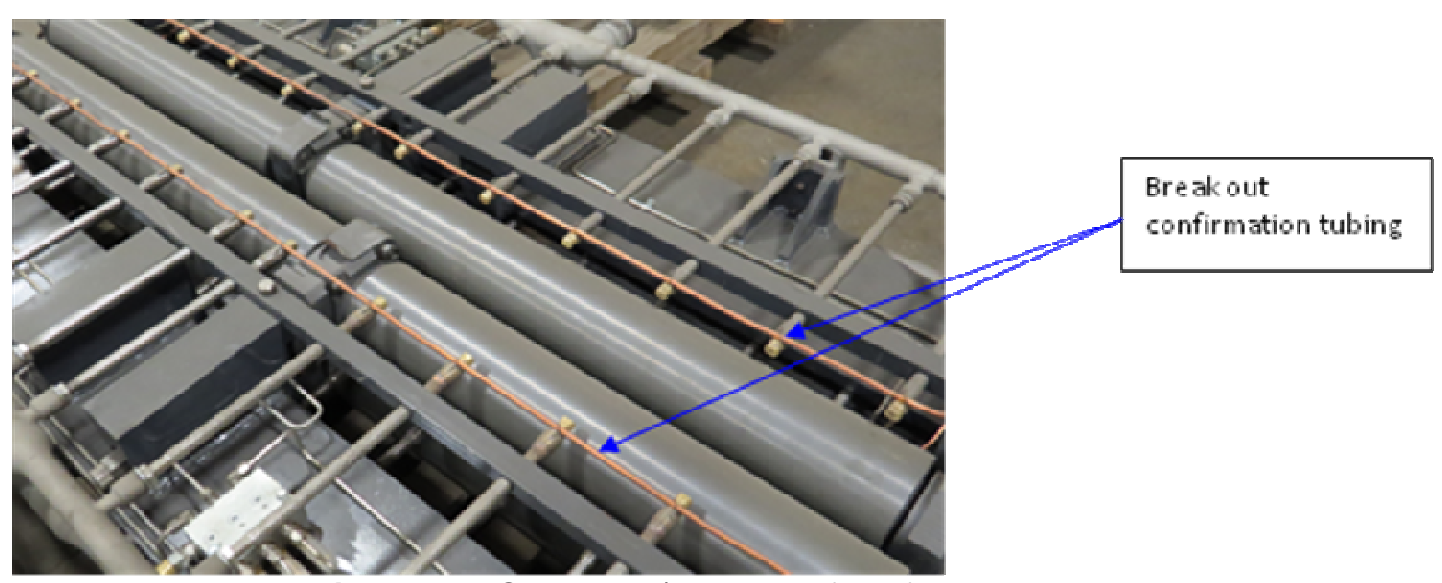

Figure 13: Staggered/split broadface foot roll design

SMS Group narrowface foot roll or lateral strand guide redesigns were made to increase support throughout campaigns lasting several hundred thousands of tons cast. The goal of these redesigns was to strengthen all components making up this sub-component, but specific focus was given to making the bracket more robust. The shaft material was modified to improve its durability and provisions were made so that the rolls would provide more consistent support for the strand. Additionally, the design was optimized so that a full length bushing could be used, and the shaft was modified so that it could be more reliably lubricated. The shaft was also coated to improve its corrosion and wear resistance, and o-rings were added at each end to help retain lubrication and keep foreign materials from entering between the shaft and the bushing. Figure 14 below is a schematic of a typical narrowface foot roll assembly showing the design improvements.

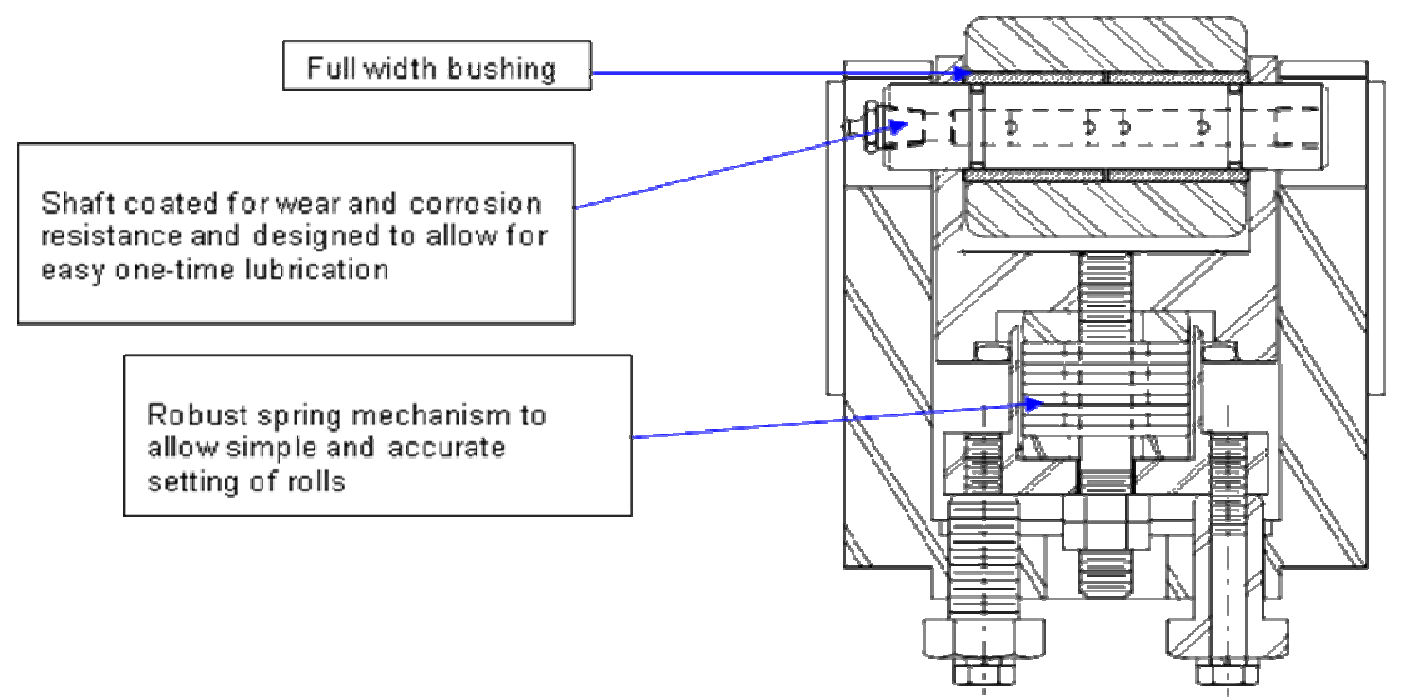

Figure 14: Schematic of narrowface foot roll assembly

\section{CONCLUSION}

There is a strong need in North America and other major steel producing markets where major capital investment in new equipment has been minimal over the past several years to make improvements to existing casting machines. In many cases, very cost effective improvements can be made to existing equipment in order to maximize the efficiency and production of an older designed continuous caster, a 
classic caster. SMS Group and its predecessor companies have been maintaining continuous casting molds for over forty years. This experience has allowed SMS Group to intimately understand the advantages and disadvantages of each design. The most vital component of the continuous caster is the mold copper design, as it has the most influence over the ability to cast a quality product. Updating to a modern copper design is less complicated than most steel producers think and the benefits are significant. Premium mold coatings such as UniGuard® and NanoGuard® allow casters to guard against exposed copper and wear while producing quality products for record campaign lengths.

Many casting machines struggle with aging steel water jackets that can exfoliate scale that can block cooling water passages inside the mold coppers. Ignoring such equipment problems can result in random longitudinal cracking issues and, in the worst of cases, can be a safety concern, SMS Group supplies water jacket improvements such as bottom plenum strainers, internal basting and subsequent powder coating to eliminate scale and corrosion issues.

Operation of a modern casting machine is highly dependent on reliable mold electrical equipment such as BOA/BOD thermocouples and end wall inclinometers; SMS Group has designed maintenance friendly solutions for optimizing such electrical systems. Increasing product size or range of product sizes that a caster can produce is valuable to an aging casting machine, and for both maintenance and production reasons, SMS Group has made a variety of improvements and upgrades to increase flexibility and reliability of the mold width drive and adjustment mechanisms. The broadface and narrowface foot rolls are sub-components of the mold that are often overlooked until mold life is extended to where they become an issue, but there are a variety of improvements that can be made to foot rolls that can make them reliable for the life of the mold.

Just because your capital budget may be low and your caster seems to get older and further out dated each passing year do not be resigned to just dealing with what you have. Allow SMS Group a chance to diagnosis your casting machine and come up with a plan to restore your classic casting machine making it more efficient and more competitive for several more years.

\section{Acknowledgments}

I would like to express thanks to the valued customers who have trusted SMS Group to make significant modifications to their continuous casting machines as presented in this paper. I would like to thank the engineers and shop employees of the Oil City Division of SMS Group for their cooperation and assistance in preparing this paper.

\section{REFERENCES}

1. C. Singh, M.K. Trinh, D. Riddle, P. Paci, G. McLarnon, C. Donovan and M. Badger, "Design and Implementation of New Moulds for the Casters at ArcelorMittal Dofasco," AISTech 2011 Proceedings.

2. J.S. Powers, W.H. Emling, and C.E. Tomazin, "Refinement of Casting Parameters for Improved Surface Quality of Cold Rolled AKDQ Sheet," ISS Steelmaking Conference Proceedings (1989), pp. 29-37.

3. C.B. Donovan, "Recent Developments in Mold Coating Technology," AISTech 2004 Proceedings, pp. 1053-1061. 
4. C.B. Donovan, W.H. Emling, M.R. Badger, J.B. Sears, "Application of Specialty Mold Coatings for Conventional, Medium, and Thin Slab Casting," AISTech 2006 Proceedings, pp. 851-859.

5. W. H. Emling, "Breakout Prevention," The Making, Shaping and Treating of Steel, 11th Edition Casting Volume, The AISE Steel Foundation, Pittsburgh, PA, 2003, pp. 1-3. 